Article

\title{
Facilitating Business Collaborations for Industrial Symbiosis: The Pilot Experience of the Sustainable Industrial Network Program in Colombia
}

\author{
Jooyoung Park ${ }^{1, *}$, Juanita Duque-Hernández ${ }^{2}$ and Nohora Díaz-Posada ${ }^{2}$ \\ 1 Graduate School of Energy and Environment (KU-KIST Green School), Korea University, Seoul 02841, Korea \\ 2 School of Management, Universidad de los Andes, Bogotá D.C. 110311, Colombia; \\ juani-du@uniandes.edu.co (J.D.-H.); nl.diaz11@uniandes.edu.co (N.D.-P.) \\ * Correspondence: jy_park@korea.ac.kr; Tel.: +82-2-3290-5914
}

Received: 30 August 2018; Accepted: 8 October 2018; Published: 11 October 2018

check for updates

\begin{abstract}
Industrial symbiosis refers to a collaborative strategy of exchanging physical resources and sharing services among industrial actors, which enhances the resource efficiency and reduces the environmental impacts of industrial operations within the network. Although it can contribute to sustainable development in emerging economies, few studies have examined the dynamics of industrial symbiosis in such regions. We initiated a capacity-building pilot program for industrial symbiosis in Colombia and formulated 20 industrial symbiosis projects with 36 companies. Based on our experience over the first year, we conducted an exploratory case study of the mechanisms that facilitate the development of industrial symbiosis. Specifically, we analyzed the nature of this facilitation and how its activities influence the key determining factors of industrial symbiosis in technical, economic, organizational, social, and institutional categories. Our facilitation approach focused on identifying opportunities and building capacity for industrial symbiosis innovation by influencing mainly the organizational and social factors. The facilitation approach requires further adjustments and experimentation to expand industrial symbiosis and to ensure the eventual implementation of these projects. This study contributes to the understanding of management perspectives of industrial symbiosis development in the context of an emerging economy.
\end{abstract}

Keywords: industrial symbiosis; collaboration; facilitation; determining factors; emerging economy; Colombia

\section{Introduction}

Industrial symbiosis has garnered increasing attention as a strategy to enhance the sustainability of industrial systems. It is a collaborative strategy in which companies exchange and reuse physical resources, such as byproducts, water, and energy, and/or share services, for example involving waste management and infrastructure [1]. By connecting business actors and their physical flows of resources, industrial symbiosis enhances the production and resource efficiencies at an inter-organizational level and increases business competitiveness by reducing costs (e.g., purchasing raw materials, waste management) and the environmental intensity of production [2]. Several studies have also identified social and other benefits of industrial symbiosis, such as job creation, learning, innovation, and regional development [3-6].

A recent review of almost 400 scholarly publications showed an uptake and increase in industrial symbiosis research over the last 20 years [7]. The majority of these papers are based on case studies of industrial symbiosis in 37 countries. Most focused on China, with others examining developed countries such as the United States, Australia, Denmark, Finland, and the United Kingdom. Few studies 
focused on developing countries, implying that the practice of industrial symbiosis and/or its studies are largely missing in such regions. According to the World Economic Outlook [8], emerging markets and developing economies encompass 154 countries, covering $86 \%$ of the world's population and $59 \%$ of global GDP. Industry in these regions is growing at significantly higher rates than it is in advanced economies [9]. Given the need for sustainable industrial transformation, industrial symbiosis is a strategy that can contribute to a circular economy and sustainable development in these regions.

Colombia is an upper-middle country, with economic growth driven largely by the mining, construction, and service sectors [10]. However, this growth has come at the cost of deforestation, biodiversity loss, and the depletion of natural resources. The resource intensity of Colombia is around $2.28 \mathrm{~kg}$ per GDP, which is 2.8 times higher than that of OECD countries [11]. Inefficiency in resource use is particularly notable in agriculture, which accounts for $55 \%$ of the country's total water consumption and generates only $6-7 \%$ of the national GDP. Most waste (about $83 \%$ ) is discarded, rather than being reused and recycled. Industry contributes to around 31\% of the national GDP [10], but suffers from low competitiveness (e.g., Colombia ranked 70th out of 140 countries in terms of a global competitiveness index in 2015) and a low level of innovation (e.g., R\&D expenditure is only about $0.2 \%$ of the national GDP) [11,12]. Faced with these challenges, Colombia set a policy goal of Green Growth in its 2014-2018 National Development Plan and embraced 92 of the 169 SDG targets across its policy priority areas [13].

As a capacity-building initiative, the Sustainable Industrial Network Program (SINP, or Red de Empresas Sostenibles/RedES, in Spanish) has been promoting sustainable transformation of the industrial network in the regions of Cundinamarca and Boyacá in Colombia. With funding from the regional environmental authority, a team of researchers and consultants at the Universidad de los Andes School of Management (UASM) has promoted the practices of cleaner production. Operating since 2013, the program has attracted the participation of more than 335 companies and has developed 339 cleaner production projects, growing into a signature initiative in the region [14]. To further expand sustainable industrial transformations, we introduced a pilot program on industrial symbiosis to the existing SINP platform. Between January and November of 2017, we developed and facilitated two capacity-building programs that included 36 companies across various sectors and led to the formulation of 20 industrial symbiosis projects for further implementation.

Given the early stage of industrial symbiosis development in Colombia, we are particularly interested in understanding the mechanisms that facilitated this development. For example, we examine what leads companies to collaborate to achieve industrial symbiosis among business actors that may not be in the traditional supply chain or in alliance partnerships [15]. In particular, how do external actors facilitate such collaborations in an emerging economy? How to promote industrial symbiosis is one of the central topics studied in the field of industrial ecology. As a result, scholars have identified key determining factors of industrial symbiosis in technical, economic, organizational, social, and institutional spheres, and presented various models of industrial symbiosis dynamics [16-18]. Boons et al. [1] integrated these models and proposed six typologies for industrial symbiosis dynamics: self-organization, organizational boundary changes, facilitation-brokerage or collective learning, pilot facilitation and dissemination, government planning, and eco-cluster development. The Colombian SINP pilot program is based broadly on the facilitation-brokerage approach in which a third-party facilitator establishes a space for companies to interact and develop industrial symbiosis. In this study, we explore the facilitation dynamics in greater detail by analyzing the nature of the facilitation and how it influences certain key factors and the development of industrial symbiosis. Therefore, the objective of our study is to provide a facilitation model for industrial symbiosis and to describe its mechanisms in the context of an emerging economy.

We first review the existing literature to understand the key factors affecting industrial symbiosis collaboration and the facilitation models. Next, we present the context of the SINP, our approach, and the results of the pilot initiative. Lastly, by analyzing the facilitation approach to industrial symbiosis development and its effects, we offer suggestions for the future development and implementation of industrial symbiosis in the context of emerging economies. 


\section{Literature Review}

Industrial symbiosis is fundamentally a problem of collaboration. Principally, it requires collaborations between business actors, but it may also involve governments and other actors, such as facilitators. The literature on industrial ecology has studied specific types of collaboration for exchanging and sharing physical resources among industrial actors. Collaboration as a general strategic issue has been studied in much broader fields, from inter-organizational management (e.g., strategic alliances and partnerships) to urban governance and public management. To understand the mechanisms of collaboration, we first review the literature on the key factors influencing the process of business collaborations and industrial symbiosis. Then, because we focus here on facilitated collaboration, we also review studies that provide facilitation models.

\subsection{Determining Factors for Industrial Symbiosis as an Inter-Organizational Collaboration}

In the field of management, studies on inter-organizational relationships have examined the issue of relationship structuring for strategic alliances and partnerships between firms, using various theoretical frameworks. Transaction cost economics explains that a firm organizes its "boundary-spanning activities" in a way that minimizes the total cost, which includes the transaction costs related to searching a partner, contracting, monitoring, and enforcing $[19,20]$. However, the theory has been criticized for focusing on cost minimization and excluding value-creation, and for considering ex-post outcomes rather than decision-making processes [21]. In addition to cost, studies have examined the role of social factors such as trust, power, norms, and culture to explain the dynamics of collaborative relationships [22-26]. For example, economic sociology explains how intentionally rational people resort to social devices because economic actions are embedded in a social structure $[27,28]$.

Studies on industrial ecology are also increasingly recognizing the important role of social and contextual factors in building industrial symbiosis. Kalundborg was the first to provide an example of industrial symbiosis, but attempts to replicate it proved unsuccessful, resulting in several abandoned projects in the United States $[29,30]$. These experiences raised the question of what determines the success or failure of industrial symbiosis. A stream of industrial symbiosis research has explored the factors that drive and/or hinder industrial symbiosis, categorizing them as technical, economic, organizational, social, and/or institutional factors (see Table 1) [31-35]. Of these factors, technical (e.g., material characteristics, availability of technology) and economic factors (e.g., costs and benefits of industrial symbiosis) are considered the minimum requirements for businesses to participate in industrial symbiosis. However, many studies also note the importance of organizational factors (e.g., awareness, attitude of managers, culture of organizations) [34-36], social factors (e.g., trust, shared value, culture of cooperation, social capital) [37-40], and institutional factors (e.g., policy, legal, and regulatory measures) [41-44]. These works argue that industrial symbiosis requires the right recipe or combination of factors, depending on the local context. The importance of these contextual factors is emphasized by the term "embeddedness". Howard-Grenville and Boons (2009) [45] proposed six types of embeddedness relevant to industrial symbiosis: cognitive, political, cultural, structural, spatial, and temporal embeddedness. Using this framework of key determining factors, we examine how the facilitation approach influences and changes these factors in the context of our case study. 
Table 1. Key determining factors of industrial symbiosis.

\begin{tabular}{|c|c|}
\hline Categories & Key Determining Factors \\
\hline Technical & $\begin{array}{l}\text { - Quality, quantity, and continuity attributes of inputs and output streams } \\
\text { - Availability of reliable and cost-efficient technologies to enable synergies } \\
\text { (e.g., in processing by-products) } \\
\text { - } \quad \text { Availability of infrastructure (e.g., pipelines) }\end{array}$ \\
\hline Economic & $\begin{array}{l}\text { - Potential economic benefits, including net cost savings (e.g., any change in } \\
\text { the cost of virgin inputs, waste management, operations, transportation, } \\
\text { and transactions) and revenue (e.g., by-product sales) } \\
\text { - Size of capital investment required and availability of funding } \\
\text { - Contribution to competitive advantage }\end{array}$ \\
\hline Organizational & $\begin{array}{l}\text { - Awareness and knowledge of the concept of industrial symbiosis and its } \\
\text { potential benefits } \\
\text { - Attitudes of the manager and/or organizational culture (e.g., openness, } \\
\text { commitment, willingness) } \\
\text { - Organizational capacity and availability of organizational resources } \\
\text { (e.g., staff, money, time) } \\
\text { - Risk perception (e.g., in disclosing information and/or } \\
\text { creating dependency) }\end{array}$ \\
\hline Social & $\begin{array}{l}\text { - } \quad \text { Level of social interaction and mental proximity, or trust } \\
\text { - } \quad \text { Capacity for communication and negotiation } \\
\text { - } \quad \text { Common, aligned strategic vision and belief } \\
\text { - } \quad \text { Balance or asymmetry in decision-making power and structure }\end{array}$ \\
\hline Institutional & $\begin{array}{l}\text { - } \quad \text { Environmental policies and standards (e.g., policy targets and interventions } \\
\text { - } \quad \text { Nor industrial symbiosis) } \\
\text { - } \quad \text { Policy instruments (e.g., taxes, fees, fines, levies, subsidies, credits) } \\
\text { - } \quad \text { Stakeholder pressure }\end{array}$ \\
\hline
\end{tabular}

\subsection{Facilitation Models}

With a diffusion of governance power, urban planning considers how to involve new actors and build collaborative relationships. A new concern is not just on how to create inter-organizational networks, but how to build cultures in which communities can collectively address regional issues [46]. Ansell and Gash [47] presented a generic model for collaborative governance, with collaborative process variables at the core. Collaboration process is highly iterative and includes feedback in the form of communication, trust, commitment, understanding, and outcomes. Other variables that define starting conditions, institutional design, and leadership represent either critical contributions to or context for the collaboration process. Of these four elements of collaboration identified by Ansell and Gash, we focus on facilitation (the "leadership" component). Our aim is to understand how this component provides essential mediation and/or facilitation for the collaborative process, often by controlling and influencing institutional design or ground rules for collaboration. Ansell and Gash [48] further presented three types of facilitative leadership distilled from the literature on collaborative governance: steward, mediator, and catalyst. They extract the attributes, skills, and strategies of leaders who initiate, guide, and steer collaborations, and then classify these according to the key roles and nature of the facilitation. Stewards establish and protect the integrity of the collaborative 
process by maintaining a wide representation of stakeholders in a neutral setting, thus lending legitimacy and providing a broad framework of transparency, inclusiveness, and outcome effectiveness. Mediators arbitrate conflicting positions to facilitate positive interactions and to nurture relationships between stakeholders. Catalysts go beyond a mediating role in that they aim to identify and exploit value-creating opportunities and, therefore, mobilize stakeholders for innovation.

Some studies on industrial symbiosis examine the roles of various types of facilitators. Hewes and Lyons [40] conducted ethnographic fieldwork to observe the roles of two individuals, or "champions", in the development of industrial symbiosis. They emphasize the importance of having locally embedded champions who develop social relationships and trust among communities. They also show how a champion's departure influences the long-term viability of industrial symbiosis. Von Malmborg [49] focuses on the knowledge-transfer role of local authorities in developing and managing regional industrial ecosystems. As an institutional anchor tenant, a local authority can link companies to consultants or technical experts (knowledge brokers) or can provide knowledge themselves (knowledge bank). Paquin and Howard-Grenville [50] inductively explored the actions of regional environmental authorities in the UK's National Industrial Symbiosis Programme (NISP) for an eight-year period. Based on observational and archival data, they grouped the NISP's facilitation actions into three categories: conversation, connection, and co-creation. Their findings show that each set of actions has a different influence on development and evolution of symbiosis. Conversation, or actions that engage a broad range of firms (e.g., building awareness and interest) and facilitate interaction spaces, appeared early in the pre-network development phase. Connection actions dominated the network development phase, when the NISP strategically introduced relevant firms around specific exchanges or deepened their involvement with firms to bring specific projects to fruition. The NISP actions eventually evolved into co-creation, which supports more time-consuming infrastructure development around important resource streams by replicating high-value symbioses and developing capacity around the processing of key regional resource streams.

Beginning with the broad question of how to promote industrial symbiosis, we first explore the facilitation approach adopted by the industrial symbiosis pilot program of the SINP. As such, we examine how the approach influences key determining factors and the outcomes of industrial symbiosis (formulation of IS projects) (see Figure 1). First, we analyze the facilitation approach using the facilitative leadership model of Ansell and Gash [48]. This provides an understanding of the nature of facilitation activities and the types of strategies used to promote the formulation of industrial symbiosis projects. Second, we examine the changes in the key determining factors of industrial symbiosis based on the observations and evaluations of program participants. We also examine the outcomes in terms of the number, type, and potential benefits of formulated projects.

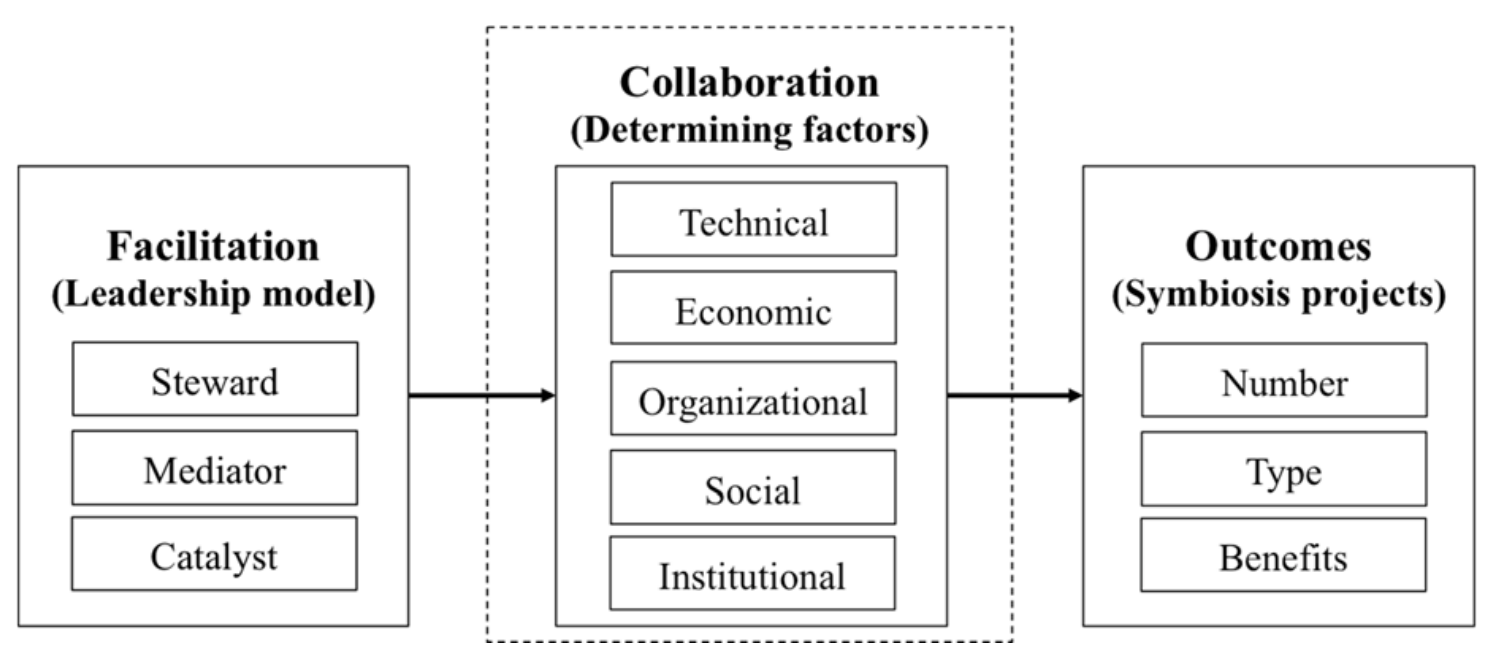

Figure 1. Conceptual model used in our study. 


\section{The Study Case and Research Methods}

We conduct an exploratory case study of the pilot initiative for industrial symbiosis introduced on the SINP platform in Colombia. The SINP initially focused on disseminating cleaner production, but over time, companies expressed an interest in additional programs and "industrial symbiosis" was chosen as the new theme. The SINP is an overarching institutional platform and benchmarked model for the industrial symbiosis pilot program, which means it uses the same institutional structure in terms of funding mechanisms, workshop structures, and facilitation. However, the program explicitly emphasizes collaboration and building capacity in its work across companies. By addressing opportunities at an inter-organizational level, the program aims to further expand sustainable transformation and its benefits.

We ran two pilot programs on industrial symbiosis: the first from January to March 2017, and the second from October to November 2017. All authors of this paper were involved in developing the pilot program and the workshop materials. We invited companies based on their size, location, and industrial sector [51], as well as on their commitment to the program. The first pilot program included 25 representatives from 13 companies across the construction, packaging, beverage, chemical, cosmetic, agriculture, and waste management sectors (see Table A1 in the Appendix A for detailed information on the companies). The second pilot program included 32 representatives from 23 companies in the flower, dairy, poultry, food, chemical, cosmetic, construction, wood, furniture, and waste management sector (see Table A2). Two of the authors led the workshops as the main facilitators and the third author observed the dynamics of the workshops. Therefore, our analysis of the facilitation approach is based on the observation, documentation, and interpretation of our own activities.

To understand how the facilitation approach may influence the key factors of industrial symbiosis, we conducted a survey at the end of the two pilot programs. The survey included questions that require evaluations using five-point Likert scales and open answers. The questions were devised to evaluate following four aspects: (1) the content of the workshops and the role of facilitators; (2) individual and organizational learning; (3) inter-organizational relationships; and (4) the motivations, drivers, and challenges of project development. Of the 57 representatives who participated in the workshops, 32 responded to the survey ( $56 \%$ response rate). We also conducted semi-structured interviews approximately nine months after the first pilot program to follow up on the status of project implementation.

With regard to the program outcomes, at the end of the workshops, we documented the industrial symbiosis projects that had been proposed and formulated successfully. We categorized these projects into three types of industrial symbiosis (i.e., byproduct exchange, utility sharing, and service sharing). Then, we estimated the economic potential (e.g., cost savings, additional revenue, and payback period) and net environmental benefits (e.g., reductions in water consumption, energy consumption, chemical use, and greenhouse gas emissions, as well as changes in waste disposal) of the projects. All data on the projects and the benefit estimates were compiled and submitted by the companies. The accuracy and reliability of the data were reviewed and checked by facilitators, to the best extent possible, which often required further discussions with the companies. Here, we considered the formulation of the projects, not their eventual implementation. One of the reasons for this is that the scope of the SINP program is limited to the operation of workshops, which end with formulations and proposals for potential projects. Project implementation is then left to the companies, which make their own decisions based on their capacity. According to the current institutional design of the SINP, our facilitation role focused primarily on project formulation; in other words, we were not involved in the implementation process. Understanding the collaboration process used to implement industrial symbiosis projects is left to future research. Owing to the exploratory nature of our case study, we examine the relationship between the facilitation, key factors, and program outcomes in a qualitative way, and supporting this with information from observations, surveys, and interviews. 


\section{Results}

\subsection{Analysis of the SINP's Facilitative Approach}

The SINP pilot program is composed of six-week long workshop sessions (see Table 2). In the first week, facilitators introduce the concept of industrial symbiosis through a game in which participants play the role of different firms and explore opportunities of industrial symbiosis. In the second week, the facilitators illustrate various cases of industrial symbiosis, explaining their approaches and associated benefits generated. Then companies engage with an auction, where a company explains their key output streams and any companies that are interested in using one of the materials express their needs. Afterward, matched companies exchange further information about the materials and examine feasibility of the material exchange inside and outside of the workshop sessions. In the third week, the facilitators explain overall collaboration processes required for industrial symbiosis. Companies are engaged with a negotiation simulation and discuss effective strategies and potential challenges of collaboration. In the fourth week, the facilitators teach how to conduct a feasibility study. By then, participating companies are expected to identify one or more opportunities for industrial symbiosis, so that they can estimate costs and benefits of the project. After one week of individual counseling and problem-solving with the facilitators, companies present the idea, feasibility, and benefits of a project in the sixth week.

Table 2. Objectives and activities of SINP's workshop sessions.

\begin{tabular}{lll}
\hline \multicolumn{1}{c}{ Session } & \multicolumn{1}{c}{ Objectives } & \multicolumn{1}{c}{ Activities } \\
\hline 1. Concept of industrial symbiosis & $\begin{array}{l}\text { To understand the concept of } \\
\text { industrial symbiosis and its link to } \\
\text { business sustainability and } \\
\text { competitiveness }\end{array}$ & $\begin{array}{l}\text { Industrial symbiosis game } \\
\text { and discussion }\end{array}$ \\
\hline 2. Benefits of industrial symbiosis & $\begin{array}{l}\text { To understand the benefits of } \\
\text { industrial symbiosis and initiate the } \\
\text { exploration of opportunities }\end{array}$ & $\begin{array}{l}\text { Waste auction and match, } \\
\text { breakfast gathering }\end{array}$ \\
\hline $\begin{array}{l}\text { 3. Collaboration process and } \\
\text { capacity for industrial symbiosis }\end{array}$ & $\begin{array}{l}\text { To understand the collaboration } \\
\text { process and capacity required for } \\
\text { industrial symbiosis }\end{array}$ & $\begin{array}{l}\text { Negotiation simulation } \\
\text { and discussion }\end{array}$ \\
\hline 4. Feasibility analysis & $\begin{array}{l}\text { To estimate the costs and benefits of } \\
\text { an industrial symbiosis project }\end{array}$ & $\begin{array}{l}\text { Benefit calculation exercise, } \\
\text { cost-benefit and context } \\
\text { analysis of a project }\end{array}$ \\
\hline 5. Project development & $\begin{array}{l}\text { To address potential issues and } \\
\text { challenges for project development }\end{array}$ & $\begin{array}{l}\text { Counseling and problem } \\
\text { solving }\end{array}$ \\
\hline 6. Project presentation & $\begin{array}{l}\text { To announce the outcome of the } \\
\text { program participation and present } \\
\text { details of the project }\end{array}$ & $\begin{array}{l}\text { Presentations and audience } \\
\text { feedback }\end{array}$ \\
\hline
\end{tabular}

Throughout six weeks of the SINP pilot program, facilitators used various approaches of all leadership types (steward, mediator, and catalyst) (see Table 3). The steward's role in establishing the institutional structure and convening the collaboration process benefited from the existing SINP platform, which is well perceived as a signature program on sustainable industrial transformation in the region. The facilitators were able to bring in a sufficient number of participants to convene the program using their existing relationships within the business communities in the region. From their experience in the earlier cleaner production program, facilitators already knew how to follow up with companies, run program activities, and provide feedback to manage the inclusiveness and transparency of the process. This aspect was supported by the high evaluations of participants on trust in the facilitators (4.52 on a five-point Likert scale) to initiate and lead the program. To establish the program's identity and image, the facilitators organized a forum before convening the workshop 
to introduce industrial symbiosis to the interested parties. The SINP program also included other activities, such as events to grant certificates and outreach channels such as the program's website, seminars, and booklets.

Table 3. The SINP's facilitation approach to industrial symbiosis analyzed using the facilitative leadership model of Ansell and Gash [48].

\begin{tabular}{|c|c|c|}
\hline $\begin{array}{c}\text { Facilitative } \\
\text { Leadership Type }\end{array}$ & $\begin{array}{l}\text { Skills and Strategies Defined } \\
\text { by Ansell and Gash [48] }\end{array}$ & The SINP's Facilitation Approach \\
\hline Steward & $\begin{array}{l}\text { - Lend reputation and social } \\
\text { capital to convene process } \\
\text { Establish the inclusiveness, } \\
\text { transparency, and neutrality } \\
\text { of process } \\
\text { - Manage image and identity } \\
\text { of collaboration }\end{array}$ & $\begin{array}{l}\text { - Lend reputation of the SINP program } \\
\text { and existing relationships with } \\
\text { businesses to initiate the program } \\
\text { - Select participants } \\
\text { - Develop and structure the program } \\
\text { - Check participation and activities } \\
\text { (e.g., calling, assignments) } \\
\text { - Provide individual/public feedback } \\
\text { - Grant certifications in a grand } \\
\text { - Closing event } \\
\text { Communication and outreach } \\
\text { (e.g., program website, } \\
\text { conferences/seminars) }\end{array}$ \\
\hline Mediator & $\begin{array}{ll}\text { - } & \text { Mediate disputes } \\
\text { - } & \text { Facilitate construction of } \\
\text { shared meaning } \\
\text { - } \quad \text { Restore process to } \\
\text { positive interaction } \\
\text { - } \quad \text { Build trust among stakeholders }\end{array}$ & $\begin{array}{l}\text { - } \quad \begin{array}{l}\text { Share case studies and reference } \\
\text { information (e.g., benefits) }\end{array} \\
\text { - Lead and control discussions for } \\
\text { positive interactions } \\
\text { - Individual counseling } \\
\text { for problem-solving } \\
\text { - Engage participants in } \\
\text { collective activities } \\
\text { - Create an informal space for } \\
\text { interaction (e.g., breakfast gathering) }\end{array}$ \\
\hline Catalyst & $\begin{array}{l}\text { Engage in systems thinking and } \\
\text { frame problems } \\
\text { Create mutually reinforcing link } \\
\text { between collaboration } \\
\text { and innovation }\end{array}$ & $\begin{array}{l}\text { - Raise awareness and interest for } \\
\text { collaboration (e.g., game, systems } \\
\text { perspective, link to competitiveness) } \\
\text { Create positive motivation for } \\
\text { symbiosis innovation } \\
\text { (e.g., emphasize leadership) } \\
\text { Develop ideas together and/or } \\
\text { provide guidance } \\
\text { - Share knowledge (e.g., benchmark } \\
\text { cases, promote discussions among } \\
\text { participants, academic knowledge } \\
\text { from the literature) } \\
\text { Teach and train necessary tools } \\
\text { (e.g., estimation of benefits, } \\
\text { feasibility studies) }\end{array}$ \\
\hline
\end{tabular}

In the SINP, the facilitators' mediating role focuses on establishing an environment that encourages positive interactions and relationship building. For example, facilitators designed activities that enabled participants to interact and build relationships (e.g., industrial symbiosis game, waste auction and bidding, breakfast gatherings) and led discussions in a constructive way (e.g., by controlling 
disrespectful comments and sharing success examples and useful knowledge). Participants found this aspect of facilitation valuable: "the facilitators' ability to promote communication and interaction" as well as "the ability to motivate and empower" both scored 4.69 on a five-point Likert scale. Facilitators did not need to resolve conflicts, mainly because disputes did not arise during the workshop sessions and the project formulation stage. This was most likely because the program established a joint goal of developing a project by the end of the workshop and companies perceived win-win benefits in pursuing industrial symbiosis. It is likely that more conflicts would arise during the implementation of an industrial symbiosis project, requiring that facilitators adopt a more active mediating role.

The facilitators played a strong role as catalysts, which was partly supported by participants' evaluations of facilitators' role in guiding and formulating projects (4.60) and in delivering new concepts and ideas (4.53). This is because the main objective of the program is to promote the development of industrial symbiosis, a type of collaborative innovation for sustainability. Here, key activities included empowering and motivating participants by introducing the concept of industrial symbiosis and its link to competitiveness, sharing knowledge and tools for change actions, and developing ideas and alternatives together.

\subsection{Influence of the SINP's Facilitation on Industrial Symbiosis Key Factors}

Table 4 lists the key determining factors, taken from the literature, and the influence of the SINP facilitation approach on each variable, evaluated qualitatively based on our observations of the workshop dynamics, survey responses, and the results of the follow-up interviews. Although technical and economic factors are considered most important in terms of motivating companies to develop projects (4.46 and 4.14 on a five-point Likert scale, respectively), the facilitation of the SINP pilot program did not focus on these factors. When inviting participants, program facilitators considered the composition of the workshop group and potential input-output matches, but could not fully control these because of the requirements of the funding agency related to workshop size and the commitment of the companies. Once the size and composition of the workshop group were determined, there were limits in exploring technical opportunities for industrial symbiosis and, therefore, the potential economic gains. In the pilot program, participating companies explored opportunity sets for industrial symbiosis based on their own knowledge and on the information shared within the group. Here, the facilitators did not actively seek technological options or funding opportunities outside of the group. Similarly, no facilitation actions were taken to change the institutional environment. Participants acknowledged potential regulatory constraints (e.g., Colombian regulations do not allow the use of water other than the public sources) and developed their projects within these legal boundaries.

The SINP's facilitation actions focus more on influencing organizational and social factors. Similarly to the SINP program on cleaner production, the pilot program focused strongly on improving awareness, changing attitudes, and enhancing organizational capacities, for example, by sharing the basic concept and necessary tools (e.g., negotiation exercises, evaluations of feasibility). The impact of these facilitative actions was supported by participants' high evaluations of their learning of the new concept (4.49) and the improvement in their skills (4.49). The survey responses also showed that participants understood the concept and potential benefits of industrial symbiosis in terms of improving resource efficiencies, relationships with stakeholders, reputation, environmental and social responsibility strategies, and, more broadly, in terms of achieving innovation and cultural changes. However, the facilitation actions did not support the decision-making processes within or across organizations. Participants evaluated obtaining necessary information from a partner organization and within an organization as the most challenging of the barriers evaluated. In particular, respondents considered it more challenging to gather information within their own organization than from a partner organization. Further investigation is needed to identify the organizational decision-making structures and processes in Colombia in order to address these barriers. 
Table 4. Influence of the SINP facilitation on key factors of industrial symbiosis.

\begin{tabular}{|c|c|}
\hline Key Factors & Influence of SINP Facilitation \\
\hline \multicolumn{2}{|l|}{ Technical factors } \\
\hline Attributes of input and output streams & Consider the composition of the group when inviting participants \\
\hline Availability of technologies & - No facilitation action \\
\hline Availability of infrastructure & - No facilitation action \\
\hline \multicolumn{2}{|l|}{ Economic factors } \\
\hline Net potential benefits (costs vs. benefits) & - No facilitation action \\
\hline Investment or availability of funding & - No facilitation action \\
\hline Contribution to competitive advantage & $+\quad$ Operate affiliated recognition program \\
\hline \multicolumn{2}{|l|}{ Organizational factors } \\
\hline Awareness and knowledge & +++ Share and simulate the concept \\
\hline Attitude and/or culture & $++\quad$ Emphasize the potential benefits \\
\hline Organizational capacity and resources & ++ Share necessary tools and guide the project development \\
\hline Risk perception & - No facilitation action \\
\hline \multicolumn{2}{|l|}{ Social factors } \\
\hline Social relationships and/or trust & $++\quad$ Create space for interaction \\
\hline Capacity for communication and negotiation & $+\quad$ Share issues during negotiation \\
\hline Alignment of strategic vision and belief & ++ Emphasize potential win-win relationships \\
\hline Balance or symmetries of power & - No facilitation action \\
\hline \multicolumn{2}{|l|}{ Institutional factors } \\
\hline Policies and regulations & No facilitation action \\
\hline Policy instruments & - No facilitation action \\
\hline Stakeholder pressure & - No facilitation action \\
\hline
\end{tabular}

In contrast to the SINP on cleaner production, the pilot program emphasized building relational capital to promote collaboration, by establishing a common vision for industrial symbiosis and creating a space for interaction and communication (e.g., joint activities and informal gatherings). About $47 \%$ of the respondents stated that they did not have previous social relationships at the individual or organizational level (e.g., did not know the person or knew only the name of the organization). However, after the program, about $81 \%$ described their relationships as "partners that share long-term interests" or "having trust and being able to continue exploring further collaboration opportunities". Most of the respondents pursued active interactions and communication with partners by sharing information through e-mails and/or phone calls (43\%) and meeting outside of the program $(28 \%)$. However, participants expressed some difficulties related to negotiations and inter-organizational arrangements. Here, facilitators did not intervene in a significant way, other than to introduce potential issues that may be encountered during negotiations.

\subsection{Outcomes of the Industrial Symbiosis Project Development}

As a result of the facilitation in the pilot programs, 20 industrial symbiosis projects were developed and proposed among 34 companies (In total, 36 companies attended and completed all workshops. Four could not formulate a project, and two new companies were drawn by program participants to formulate projects (see "External companies" in Figure A2). These two external companies attended one workshop) (Appendix B shows the network diagrams of the symbiosis projects). Given that 36 companies participated in the pilot programs, almost all were involved with at least one project. It may be those companies that failed to design a project found limited technical opportunities for symbiosis, given the composition of the group [52]. For example, a consulting company for energy efficiency was not able to find a symbiosis partner because there were no proposals for energy-sharing projects. Although many instances of industrial symbiosis were reported among the chemical companies around the world, the chemical company participated in the pilot program failed to develop a symbiosis project. This may be because most of the participating companies operated within the agricultural 
sector, not the chemical sector. This implies that facilitators need to carefully design the size and composition of workshop groups to maximize opportunities for industrial symbiosis.

The 20 symbiosis projects were estimated to generate economic benefits worth approximately USD 760,000 (i.e., COP 2282 million), considering both cost savings and additional revenue. On average, each project was estimated to generate about USD 38,000, with a payback period of three months (As a comparison, the average economic benefits of the 339 cleaner production projects formulated under the SINP were USD 28,760, with an average payback period of 14 months). This level of economic benefits is significant for many SMEs in an emerging economy. Thus, many of these industrial symbiosis projects may be implementable from an economic perspective (In the case of cleaner production, about $58 \%$ of the projects designed under the SINP were implemented). In terms of environmental benefits, 20 projects estimated they would prevent 7207 tons of waste disposal and 1126 tons of greenhouse gas emissions, and would reduce energy consumption by $619,500 \mathrm{kWh}$ and water consumption by $146,000 \mathrm{~m}^{3}$ per year. These are considerable potential benefits. For example, the saving in waste disposal is equivalent to the average waste generated by 23,249 Colombians per year, and the energy reduction is equivalent to the average electricity consumption of 319 Colombian households per year. This shows that industrial symbiosis can generate considerable economic and environmental benefits in a collective way. At the project level, the facilitation approach did not necessarily promote the development of larger projects with larger benefits. However, future research should explore how facilitators can increase the benefits of industrial symbiosis.

The proposed industrial symbiosis projects include 17 byproduct exchanges, two service-sharing projects, and one wastewater project. Of the 17 byproduct exchanges, nine focused on reusing packaging and delivery materials made of wood, plastic, paper, or glass. The focus on packaging material may show that projects were first developed in a way that did not require considerable upfront investment or changes. This may also imply that there are many technically feasible reuse opportunities that have not yet been realized. In addition, two service-sharing projects show considerable potential economic benefits. These benefits are derived mainly from better rates for waste management, because the companies enhanced their power by negotiating collectively and increasing the volume of waste. This may reflect the lack of maturity of the waste market (e.g., there are only a few waste management service providers with varying level of service), as well as its level of information asymmetry (e.g., companies do not have the information about standard market rates). This is particularly likely in emerging markets, which are characterized by weaker regulatory enforcement and market irregularities. On the other hand, we observed only one case of wastewater reuse, and no cases of energy sharing. Despite opportunities being available, energy and water symbiosis may be more difficult to establish owing to the heavy investment required in infrastructure, such as pipelines and equipment [32].

Analyzing the relationship between company size and project outcomes, we find that projects with larger benefits tend to involve large companies. This is probably because of the greater opportunities for waste reuse and service sharing in large companies. Companies with processing facilities (e.g., waste processing or boilers) tend to be located at the center of the industrial symbiosis network, participating in several projects. This shows the important role of "scavenger" or "decomposer" businesses in closing material loops [53]. Compared with the first pilot program, the second program involved more companies from the agricultural and food sectors and the projects were smaller in terms of economic and environmental benefits. Thus, specific combinations of industrial sectors and/or company sizes might limit the technical opportunities for industrial symbiosis.

\section{Discussion}

In this pilot program, facilitators focused on identifying value-creating opportunities and capacity building (catalyst role), creating a space for interactions and relationship building (mediator role), and establishing a structure and convening the process (steward role). This is similar to the "facilitation-brokerage" model [1], which was also observed in the early phase of the NISP 
program [31,50]. Industrial symbiosis projects emerged through voluntary interactions among participants in a space established by facilitators, rather than being directed by intentions or goals. Rather than presenting solutions, facilitators encouraged participants to develop their own projects within a given period. To do so, they shared concepts and tools, encouraged participation, checked on the completion of activities, made phone calls, and reviewed calculations. In addition, the space for interaction and the collective development of projects, called the "institutional design" by Ansell and Gash [47], seemed effective in providing peer pressure to a certain level. Several companies that initially found it difficult to find a project were "pushed" by groups that had already done so until they were successful. However, unlike the NISP approach, our facilitation targeted a smaller group of companies and promoted collaboration through activities that required greater participation (e.g., exercises and assignments). This facilitation approach mobilized most participating companies to formulate industrial symbiosis projects in an emerging economy.

Further analysis of the impact of facilitation on the key industrial symbiosis factors shows that the SINP facilitation focused on changing variables in the organizational and social categories. This seems natural, because these variables are more manageable, and many are associated with the concept of "capacity", including collaborative capacity [54] and institutional capacity [46]. The concept of institutional capacity has been applied previously to industrial symbiosis systems [55-57]. Three dimensions of institutional capacity are closely related to the organizational and social factors identified in this study: knowledge capacity (i.e., the ability to acquire and use information about feasible symbiotic linkages); relational capacity (i.e., the ability to enhance opportunities for industrial symbiosis by reducing transaction costs through increased trust and mutual understanding); and mobilization capacity (i.e., the ability to activate relevant actors and attract the resources necessary to realize the exchange). Therefore, future studies may wish to explore how various models of facilitation enhance the institutional capacity of industrial symbiosis systems. Changing the institutional environment was not within the scope of the Colombian SINP program. However, other industrial symbiosis cases and programs are more actively involved in regulatory changes and support, such as those in Korea [58] and China [59]. Finally, in order to increase technically feasible and economically viable opportunities for industrial symbiosis, facilitators need to play a more active role in searching for partners, technological options, and funding opportunities, even outside the program. This requires both careful considerations of who participates in the workshops and greater technical knowledge about specific industrial processes and/or materials from external experts and participants. In the case of the NISP, facilitators adopted goal-directed processes in the latter stages to develop larger-scale projects and thus, were more involved in the formulation of project ideas [50].

This study explored the facilitation approach adopted in the Colombian SINP pilot program in detail in terms of its nature and influence on the key determining factors of industrial symbiosis. We presented a facilitation approach that differs from the facilitation models used in programs such as the NISP and, therefore, adds to the field of industrial symbiosis. However, the early stage of the pilot program drew on a limited number of samples and, therefore, the findings need to be interpreted with caution. It is crucial to observe whether these proposed projects are implemented. According to our follow-up interviews, none of the companies have yet implemented the symbiosis projects for various reasons, such as conflicts arising from power asymmetry, the absence of a person in charge, a lack of leadership, and/or unexpected barriers. Many participants expressed the need for additional guidance during project implementation. Thus, it seems that facilitators need to play a more active role as mediators by intervening in negotiations and in conflict resolution. This raises an important question about the role of facilitators during project implementation in terms of the types of facilitation activities needed. This may require changes to the current institutional structure.

We will continue with the program on industrial symbiosis with more companies across various sectors. As the program expands, the facilitation approach will need to be adjusted. Cumulative data and information obtained from the program will also allow us to improve our understanding of the industrial symbiosis dynamics and the underlying decision-making processes in an emerging economy. 
Future studies need to examine the relationships between relevant variables in a quantitative way and the different forms of capacity. The capacity or competence of the facilitators can also be the topic of future research [60].

\section{Conclusions}

Industrial symbiosis was introduced to the SINP as a collaborative approach that contributes to the sustainable transformation of industrial production in Colombia. As a result of the pilot program with 36 companies, 20 projects were proposed and designed. We examined how the facilitation approach adopted by the program drove the development of industrial symbiosis projects by analyzing a facilitation model and its impact on the key factors of industrial symbiosis, as identified from the literature. Our analysis showed that the facilitation approach adopted the roles of catalyst, steward, and mediator, and focused on identifying value-creating opportunities and building capacity for project formulation. This facilitation influenced and changed organizational and social variables, leading to the formulation of projects by most participating companies. Our findings contribute to a more detailed understanding of the facilitation approach to industrial symbiosis in the early stage of the Colombian SINP initiative, but more research is needed to corroborate the findings with larger samples from diverse contexts. Further research would help understand the full dynamics of industrial symbiosis development and implementation as well as the underlying decision-making processes.

Author Contributions: All authors contributed to the design and development of the pilot program and the conceptualization of this research. J.P. conducted the literature review, developed analytical frameworks, and wrote the first draft. J.D.-H. was in charge of overall program administration and served as a facilitator of the program. N.D.-P. served as a facilitator of the program, conducted surveys and interviews, compiled and analyzed the data. All the authors reviewed, edited and approved the final manuscript.

Funding: This research received no external funding. The APC was funded by the KU-KIST Graduate School Project.

Acknowledgments: Authors would like to thank Bart van Hoof for his constructive discussions and comments and Alex Saer for his support in the development of the program.

Conflicts of Interest: The authors declare no conflict of interest. The funders had no role in the design of the study; in the collection, analyses, or interpretation of data; in the writing of the manuscript, and in the decision to publish the results.

\section{Appendix A. List of Companies That Participated in the Industrial Symbiosis Program}

Table A1. Profiles of the participating companies in the first pilot program.

\begin{tabular}{cccc}
\hline Company Number & Size $^{\mathbf{1}}$ & Sector & Location \\
\hline Company 1 & Large & Food processing (coffee) & Bogotá \\
Company 2 & Large & Engineering, construction & Bogotá \\
Company 3 & Small & Waste management & Bogotá \\
Company 4 & Large & Beverage (soft drinks) & Tocancipá \\
Company 5 & Large & Chemical (specialty) & Tocancipá \\
Company 6 & Large & Packaging, container & Tocancipá \\
Company 7 & Medium & Gas supply & Tocancipá \\
Company 8 & Medium & Packaging, container & Tocancipá \\
Company 9 & Large & Food processing (dairy) & Sopó \\
Company 10 & Large & Glass & Soacha \\
Company 11 & Large & Agriculture (flower) & El Rosal \\
Company 12 & Large & Agriculture (poultry) & Cajicá \\
Company 13 & Small & Construction supplies & Madrid \\
\hline
\end{tabular}

1 Company size: Large (more than 200 employees and with more than 30,000 minimum wages in assets), Medium (between 51 and 200 employees and with 5000 to 30,000 minimum wages in assets), and Small (between 11 and 50 employees and with 500 to 5000 minimum wages in assets). 
Table A2. Profiles of the participating companies in the second pilot program.

\begin{tabular}{|c|c|c|c|}
\hline Company Number & Size $^{1}$ & Sector & Location \\
\hline Company 14 & Small & Industrial association (flower) & Bogotá \\
\hline Company 15 & Medium & Styrofoam & Tocancipá \\
\hline Company 16 & Large & Food (dairy) & Cajicá \\
\hline Company 17 & Medium & Chemical & Mosquera \\
\hline Company 18 & Micro & Packaging & Cajicá \\
\hline Company 19 & Large & Food & Cota \\
\hline Company 20 & Large & Construction and home supplies & Sopó \\
\hline Company 21 & Medium & Agriculture (flower) & Chía \\
\hline Company 22 & Small & Waste management (organic waste) & Bojacá \\
\hline Company 23 & Micro & Agriculture (mushroom) & San Francisco \\
\hline Company 24 & Small & Consulting (energy efficiency) & Funza \\
\hline Company 25 & Large & Curtains & Tenjo \\
\hline Company 26 & Large & Furniture & Funza \\
\hline Company 27 & Large & Agriculture (flower) & Nemocón \\
\hline Company 28 & Micro & Flower, consulting & Chía \\
\hline Company 29 & Large & Cosmetic & \\
\hline Company 30 & Small & Agriculture (poultry) & Saboyá \\
\hline Company 31 & Large & Chemical (agriculture polyethylene films) & \\
\hline Company 32 & Large & Food (bakery and snacks) & Mosquera \\
\hline Company 33 & Large & Wood & Madrid \\
\hline Company 34 & Medium & Restaurant & Bogotá \\
\hline Company 35 & Medium & Agriculture (flower) & Funza \\
\hline Company 36 & Large & Food (Bakery and snacks) & Mosquera \\
\hline
\end{tabular}

${ }^{1}$ Company size: Large (more than 200 employees and with more than 30,000 minimum wages in assets), Medium (between 51 and 200 employees and with 5000 to 30,000 minimum wages in assets), and Small (between 11 and 50 employees and with 500 to 5000 minimum wages in assets).

\section{Appendix B. Industrial Symbiosis Projects from the Pilot Program}

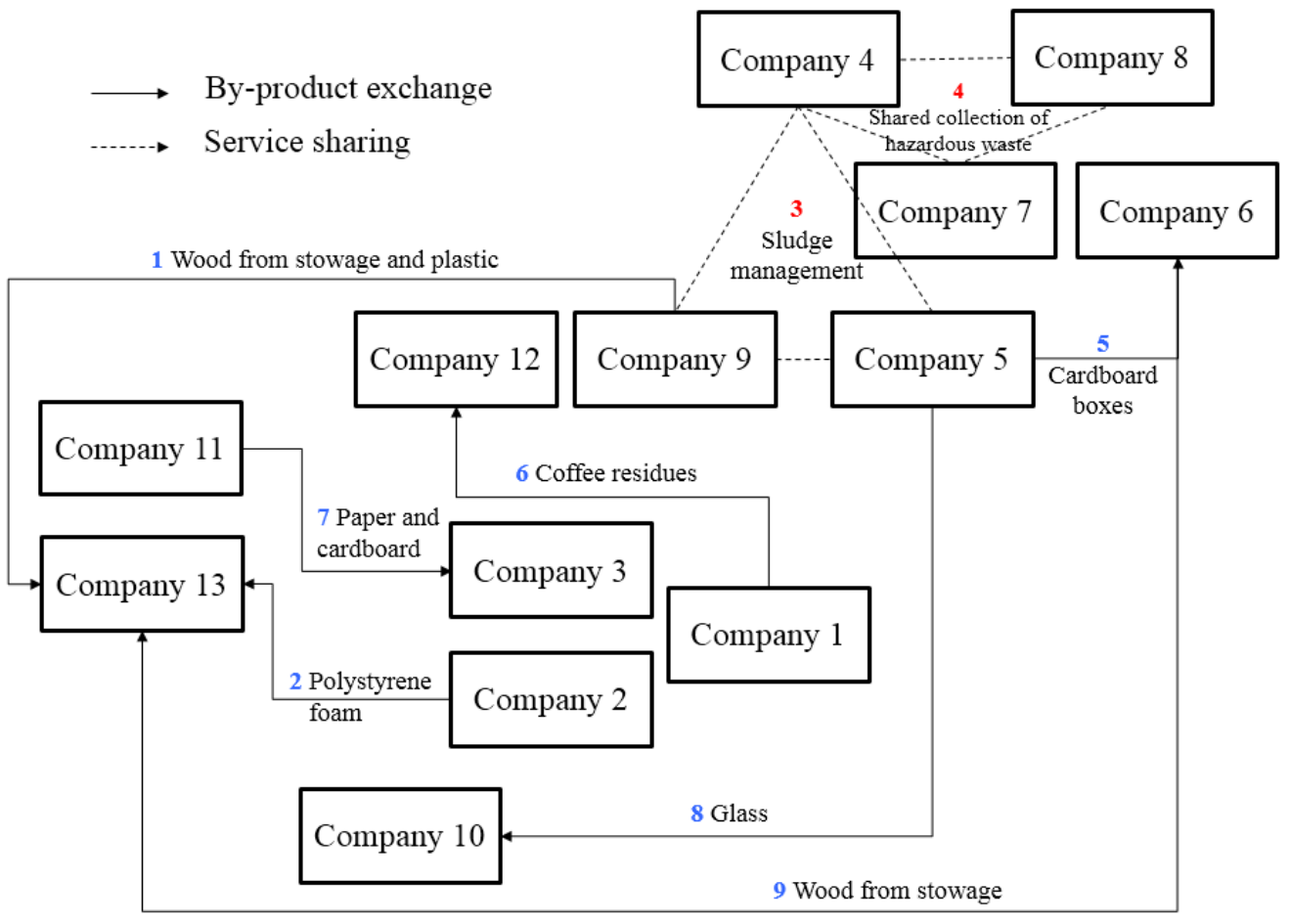

Figure A1. A network of proposed industrial symbiosis projects from the first pilot program. The location of the companies in the network reflects the actual geographical and spatial arrangements of their facilities. 


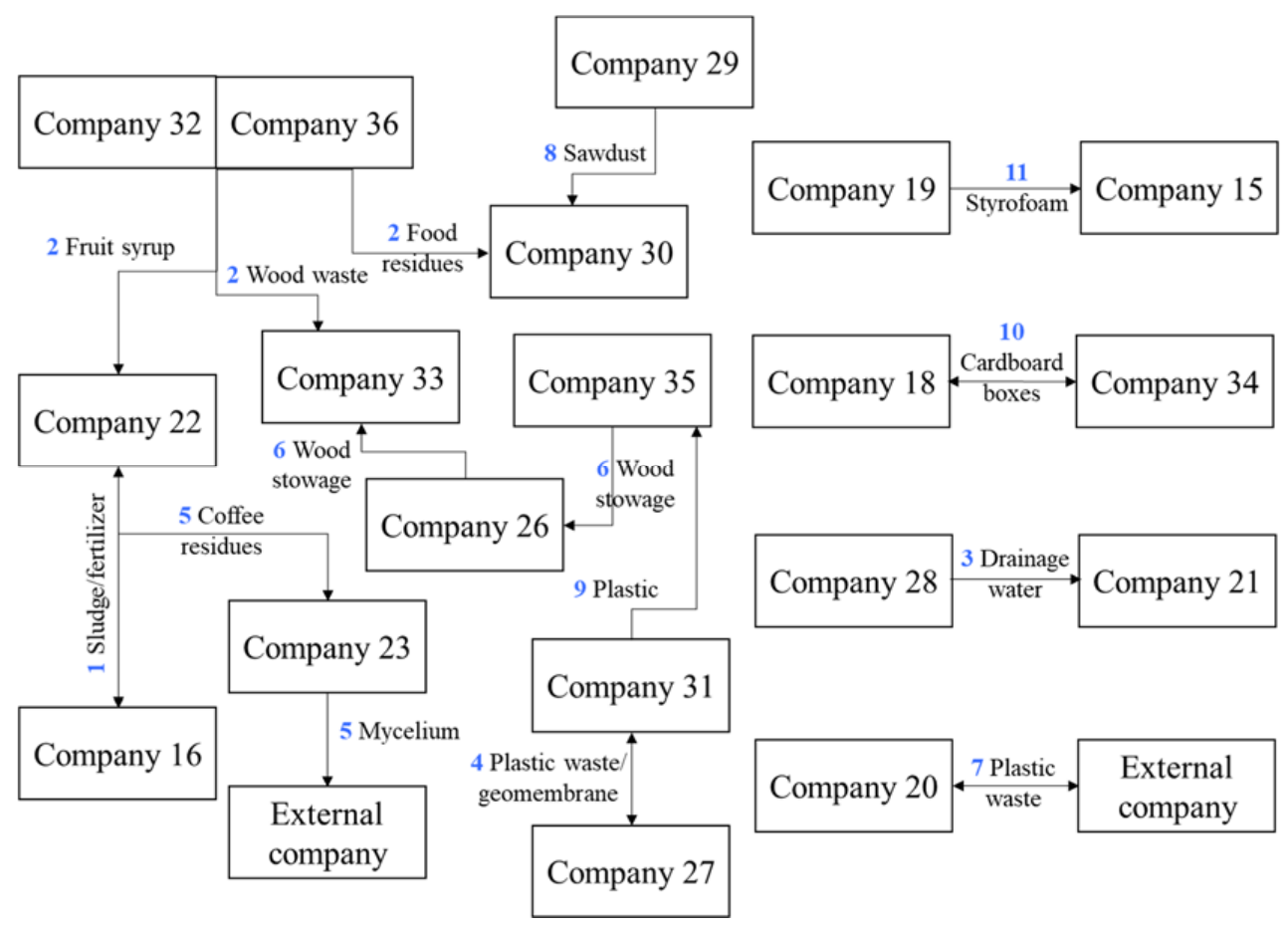

Figure A2. A network of proposed industrial symbiosis projects from the second pilot program. The location of the companies in the network reflects the actual geographical and spatial arrangements of their facilities.

\section{References}

1. Boons, F.; Chertow, M.; Park, J.; Spekkink, W.; Shi, H. Industrial symbiosis dynamics and the problem of equivalence: Proposal for a comparative framework. J. Ind. Ecol. 2016, 21, 938-952. [CrossRef]

2. Park, J.Y.; Park, H.S. Securing a competitive advantage through industrial symbiosis development the case of steam networking practices in ulsan. J. Ind. Ecol. 2014, 18, 677-683. [CrossRef]

3. Deutz, P.; Gibbs, D. Industrial ecology and regional development: Eco-industrial development as cluster policy. Reg. Stud. 2008, 42, 1313-1328. [CrossRef]

4. Ristola, P.; Mirata, M. Industrial symbiosis for more sustainable, localised industrial systems. Prog. Ind. Ecol. 2007, 4, 184-204. [CrossRef]

5. Mirata, M.; Emtairah, T. Industrial symbiosis networks and the contribution to environmental innovation-The case of the landskrona industrial symbiosis programme. J. Clean. Prod. 2005, 13, 993-1002. [CrossRef]

6. Harris, S.; Pritchard, C. Industrial ecology as a learning process in business strategy. Prog. Ind. Ecol. Int. J. 2004, 1, 89-111. [CrossRef]

7. Chertow, M.; Park, J.Y. Scholarship and practice in industrial symbiosis: 1989-2014. In Taking Stock of Industrial Ecology; Clift, R., Druckman, A., Eds.; Springer International Publishing: Berlin, Germany, 2016; pp. 87-116.

8. International Monetary Fund. World Economic Outlook: Cyclical Upswing, Structural Change; International Monetary Fund: Washington, DC, USA, 2018.

9. United Nations Industrial Development Organization (UNIDO). World Manufacturing Production; United Nations Industrial Development Organization: Vienna, Austria, 2018.

10. Central Intelligence Agency. The World Factbook: Colombia; Central Intelligence Agency: Langley, VA, USA, 2018.

11. DNP; GGGI. Diagnóstico de Crecimiento Verde: Análisis Macroeconómico y Evaluación del Potencial de Crecimento Verde; Departamento Nacional de Planeación: Bogotá, DC, USA, 2017.

12. Sachs, J.; Schmidt-Traub, G.; Kroll, C.; Lafortune, G.; Fuller, G. Sdg Index and Dashboards Report 2018; Bertelsmann Stiftung and Sustainable Development Solutions Network: New York, NY, USA, 2018. 
13. DNP; GGGI. Crecimiento Verde Para Colombia: Elementos Conceptuales y Experiencias Internacionales; Departamento Nacional de Planeación: Bogotá, DC, USA, 2016.

14. RedES-CAR. Comunidad de Práctica Para el Crecimiento Verde. Available online: https: / / administracion.uniandes.edu.co/index.php/es/facultad/sobre-la-facultad/eventos/icalrepeat. detail/2018/03/06/176/-/- (accessed on 5 October 2018).

15. Chertow, M.R. Industrial symbiosis: Literature and taxonomy. Annu. Rev. Energy Environ. 2000, 25, $313-337$. [CrossRef]

16. Baas, L.W.; Boons, F.A. An industrial ecology project in practice: Exploring the boundaries of decision-making levels in regional industrial systems. J. Clean. Prod. 2004, 12, 1073-1085. [CrossRef]

17. Chertow, M.; Ehrenfeld, J. Organizing self-organizing systems: Toward a theory of industrial symbiosis. J. Ind. Ecol. 2012, 16, 13-27. [CrossRef]

18. Doménech, T.; Davies, M. The role of embeddedness in industrial symbiosis networks: Phases in the evolution of industrial symbiosis networks. Bus. Strateg. Environ. 2011, 20, 281-296. [CrossRef]

19. Barringer, B.R.; Harrison, J.S. Walking a tightrope: Creating value through interorganizational relationships. J. Manag. 2000, 26, 367-403. [CrossRef]

20. Williamson, O.E. The economics of organization: The transaction cost approach. Am. J. Sociol. 1981, 87, 548-577. [CrossRef]

21. Lorenzoni, G.; Lipparini, A. The leveraging of interfirm relationships as a distinctive organizational capability: A longitudinal study. Strateg. Manag. J. 1999, 20, 317-338. [CrossRef]

22. Zaheer, A.; McEvily, B.; Perrone, V. Does trust matter? Exploring the effects of interorganizational and interpersonal trust on performance. Organ. Sci. 1998, 9, 141-159. [CrossRef]

23. Ring, P.S.; Van de Ven, A.H. Structuring cooperative relationships between organizations. Strateg. Manag. J. 1992, 13, 483-498. [CrossRef]

24. Lee, Y.; Cavusgil, S.T. Enhancing alliance performance: The effects of contractual-based versus relational-based governance. J. Bus. Res. 2006, 59, 896-905. [CrossRef]

25. Benton, W.C.; Maloni, M. The influence of power driven buyer/seller relationships on supply chain satisfaction. J. Oper. Manag. 2005, 23, 1-22. [CrossRef]

26. Rooks, G.; Raub, W.; Selten, R.; Tazelaar, F. How inter-firm co-operation depends on social embeddedness: A vignette study. Acta Sociol. 2000, 43, 123-137. [CrossRef]

27. Granovetter, M. Economic action and social structure: The problem of embeddedness. Am. J. Sociol. 1985, 91, 481-510. [CrossRef]

28. Beckert, J. What is sociological about economic sociology? Uncertainty and the embeddedness of economic action. Theory Soc. 1996, 25, 803-840. [CrossRef]

29. Gibbs, D.; Deutz, P. Implementing industrial ecology? Planning for eco-industrial parks in the USA. Geoforum 2005, 36, 452-464. [CrossRef]

30. Heeres, R.R.; Vermeulen, W.J.V.; de Walle, F.B. Eco-industrial park initiatives in the USA and the netherlands: First lessons. J. Clean. Prod. 2004, 12, 985-995. [CrossRef]

31. Mirata, M. Experiences from early stages of a national industrial symbiosis programme in the UK: Determinants and coordination challenges. J. Clean. Prod. 2004, 12, 967-983. [CrossRef]

32. Yu, C.; De Jong, M.; Dijkema, G.P.J. Process analysis of eco-industrial park development-The case of tianjin, china. J. Clean. Prod. 2014, 64, 464-477. [CrossRef]

33. Walls, J.L.; Paquin, R. Organizational perspectives of industrial symbiosis: A review and synthesis. Organ. Environ. 2015, 28, 32-53. [CrossRef]

34. Sakr, D.; Baas, L.; El-Haggar, S.; Huisingh, D. Critical success and limiting factors for eco-industrial parks: Global trends and egyptian context. J. Clean. Prod. 2011, 19, 1158-1169. [CrossRef]

35. Fichtner, W.; Tietze-Stöckinger, I.; Frank, M.; Rentz, O. Barriers of interorganisational environmental management: Two case studies on industrial symbiosis. Prog. Ind. Ecol. Int. J. 2005, 2, 73-88. [CrossRef]

36. Prosman, E.J.; Wæhrens, B.V.; Liotta, G. Closing global material loops: Initial insights into firm-level challenges. J. Ind. Ecol. 2017, 21, 641-650. [CrossRef]

37. Ashton, W. Understanding the organization of industrial ecosystems: A social network approach. J. Ind. Ecol. 2008, 12, 34-51. [CrossRef]

38. Gibbs, D. Trust and networking in inter-firm relations: The case of eco-industrial development. Local Econ. 2003, 18, 222-236. [CrossRef] 
39. Jacobsen, N.B. Do social factors really matter when companies engage in industrial symbiosis? Prog. Ind. Ecol. 2007, 4, 440-462. [CrossRef]

40. Hewes, A.; Lyons, D.I. The humanistic side of eco-industrial parks: Champions and the role of trust. Reg. Stud. 2008, 42, 1329-1342. [CrossRef]

41. Gibbs, D.; Deutz, P. Reflections on implementing industrial ecology through eco-industrial park development. J. Clean. Prod. 2007, 15, 1683-1695. [CrossRef]

42. Jacobsen, N.B.; Anderberg, S. Understanding the evolution of industrial symbiotic networks: The case of kalundborg. In Economics of Industrial Ecology: Materials, Structural Change, and Spatial Scales; Jeroen, C.J.M., Bergh, V.D., Janssen, M.A., Eds.; The MIT Press: Cambridge, MA, USA, 2004; pp. 313-336.

43. Ehrenfeld, J.; Gertler, N. Industrial ecology in practice: The evolution of interdependence at kalundborg. J. Ind. Ecol. 1997, 1, 67-79. [CrossRef]

44. Costa, I.; Ferrao, P. A case study of industrial symbiosis development using a middle-out approach. J. Clean. Prod. 2010, 18, 984-992. [CrossRef]

45. Howard-Grenville, J.; Boons, F. The social embeddedness of industrial ecology: Exploring the dynamics of industrial ecosystems. In The Social Embeddedness of Industrial Ecology; Edward Elgar Publishing Ltd.: Cheltenham, UK, 2009; pp. 273-282.

46. Healey, P. Building institutional capacity through collaborative approaches to urban planning. Environ. Plan. A Econ. Space 1998, 30, 1531-1546. [CrossRef]

47. Ansell, C.; Gash, A. Collaborative governance in theory and practice. J. Public Admin. Res. Theory 2008, 18, 543-571. [CrossRef]

48. Ansell, C.; Gash, A. Stewards, mediators, and catalysts: Toward a model of collaborative leadership. Innov. J. Public Sect. Innov. J. 2012, 17, 21.

49. Von Malmborg, F. Networking for knowledge transfer: Towards an understanding of local authority roles in regional industrial ecosystem management. Bus. Strateg. Environ. 2004, 13, 334-346. [CrossRef]

50. Paquin, R.L.; Howard-Grenville, J. The evolution of facilitated industrial symbiosis. J. Ind. Ecol. 2012, 16, 83-93. [CrossRef]

51. Chertow, M.; Park, J. Reusing nonhazardous industrial waste across business clusters. In Waste; Elsevier Inc.: Amsterdam, The Netherlands, 2011; pp. 197-206.

52. Chertow, M.; Park, J. Reusing nonhazardous industrial waste across business clusters. In Waste: A Handbook for Management; Letcher, T., Vallero, D., Eds.; Academic Press: Boston, MA, USA, 2011; pp. 197-206.

53. Geng, Y.; Côté, R.P. Scavengers and decomposers in an eco-industrial park. Int. J. Sustain. Dev. World Ecol. 2002, 9, 333-340. [CrossRef]

54. Huxham, C. Collaborative capability: An intra-organizational perspective on collaborative advantage. Public Money Manag. 1993, 13, 21-28. [CrossRef]

55. Boons, F.; Spekkink, W. Levels of institutional capacity and actor expectations about industrial symbiosis: Evidence from the dutch stimulation program 1999-2004. J. Ind. Ecol. 2012, 16, 61-69. [CrossRef]

56. Spekkink, W. Institutional capacity building for industrial symbiosis in the canal zone of zeeland in the netherlands: A process analysis. J. Clean. Prod. 2013, 52, 342-355. [CrossRef]

57. Wang, Q.; Deutz, P.; Chen, Y. Building institutional capacity for industrial symbiosis development: A case study of an industrial symbiosis coordination network in China. J. Clean. Prod. 2017, 142, 1571-1582. [CrossRef]

58. Park, J.M.; Park, J.Y.; Park, H.-S. A review of the national eco-industrial park development program in Korea: Progress and achievements in the first phase, 2005-2010. J. Clean. Prod. 2016, 114, 33-44. [CrossRef]

59. Geng, Y.; Zhang, P.; Côté, R.P.; Fujita, T. Assessment of the national eco-industrial park standard for promoting industrial symbiosis in china. J. Ind. Ecol. 2009, 13, 15-26. [CrossRef]

60. Dobroszek, J.; Mourao, P.; Grzesiak, L. Identification of the similarities and differences of logistics controller, manager and specialist: A study based on a content analysis. Int. J. Logist. Manag. 2018. [CrossRef]

(C) 2018 by the authors. Licensee MDPI, Basel, Switzerland. This article is an open access article distributed under the terms and conditions of the Creative Commons Attribution (CC BY) license (http:/ / creativecommons.org/licenses/by/4.0/). 